\title{
Corrosion performance of graphene oxide coated 304 SS in PEMFC environment
}

\author{
Pramod Mandal $^{1} \cdot$ N Usha Kiran ${ }^{2,3} \cdot$ Uttam K Chanda $^{4} \cdot$ Soobhankar Pati $^{4} \cdot$ Sudesna Roy $^{1}$ (D)
}

Received: 23 December 2020 / Accepted: 21 June 2021

Published online: 30 June 2021

(c) The Author(s) 2021 OPEN

\begin{abstract}
In this work, an electrophoretic deposition technique was used to deposit graphene oxide (GO) on 304 stainless steel. Its corrosion performance was evaluated in a simulated polymer electrolyte membrane fuel cell environment. The corrosion current density $\left(\mathrm{i}_{\text {corr }}\right.$ ) and interfacial contact resistance (ICR) were measured at $8.9 \mu \mathrm{A} / \mathrm{cm}^{2}$ and $19.3 \mathrm{~m} \Omega \mathrm{cm}^{2}$, respectively. The $\mathrm{i}_{\text {corr }}$ of GO coated $304 \mathrm{SS}$ is several orders lower than bare SS 304. Similarly, the ICR of GO coated 304SS is nearly half of bare $304 \mathrm{SS}$ at a compaction pressure of $150 \mathrm{~N} / \mathrm{cm}^{2}$. The potentiodynamic polarization plot indicates the prevalence of multiple corrosion mechanisms. A prolonged corrosion study for 30 days immersed in the simulated PEM cell environment shows the formation of rounded pits that corroborate the activity of pitting corrosion.
\end{abstract}

Keywords Electrophoretic deposition · $304 \mathrm{SS}$ - Graphene oxide (GO) · Corrosion resistance · Tafel plot

\section{Introduction}

Bipolar plates (BPPs) are key components in a polymer electrolyte membrane fuel cell (PEMFC) stack. Graphite has been widely used to fabricate the BPPs. However, the cost of graphite BPPs does not meet the cost targets of the United States Department of Energy-2020, especially for automobile applications. Graphite BPPs are expensive because it is difficult to machine flow channels on the surface due to their low flexural strength [1]. To prevent damage during machining, thicker plates are used, adding to the material cost and machining expense. Metallic BPPs can potentially replace graphite BPPs, and towards that, US-DOE has specified the weight, cost, flexural strength, and corrosion resistance of the replacement material [2]. The cost of the BPP, including material and manufacturing, should be less than $\$ 3 / \mathrm{kW}$, weight $<0.4 \mathrm{~kg} / \mathrm{kW}$, corrosion current density $<1 \mu \mathrm{A} / \mathrm{cm}^{2}$ in the cathodic environment, and interfacial contact resistance (ICR) $<20 \mathrm{~m} \Omega \mathrm{cm}^{2}$ as per the US-DOE 2020 targets. Therefore, it is necessary to develop cost-effective yet corrosion-resistant materials for making the next-generation BPPs.

Metals, polymers, and composites have been widely studied for replacing conventional graphite BPPs. Metals like titanium, aluminum, and steel have been evaluated both ex-situ and in-situ for BPP applications, and it is generally inferred that metals although are compliant in cost and weight, do not meet the required corrosion resistance [3]. Composites with graphite, carbon nanotubes, and graphene reinforced polymer composites are corrosion resistant but have poor electrical conductivity $[4,5]$. With these challenges, the most likely replacement of graphite BPP is a coated or surface modified steel, stainless steel, and aluminum. The coating is expected to increase the corrosion

Sudesna Roy, sudesna.roy@gmail.com | 'School of Mechanical Engineering, KIIT University, Bhubaneswar, Odisha 751024, India. ${ }^{2}$ Academy of Scientific and Innovative Research (AcSIR), Ghaziabad, Uttar Pradesh 201002, India. ${ }^{3}$ Materials Chemistry Department, CSIR-IMMT, Bhubaneswar, Odisha 751013, India. ${ }^{4}$ School of Minerals, Metallurgical \& Materials Engineering, IIT Bhubaneswar, Bhubaneswar, India. 
resistance while keeping the ICR and cost within the USDOE targets [2].

Many sophisticated coatings and surface modification techniques like physical vapor deposition (PVD) [6], chemical vapor deposition (CVD) [7], plasma nitridation [8] as well as cost-effective techniques like case carburization [8, 9], electrodeposition [10] etc. have been proposed to improve the corrosion resistance of the metallic BPPs. Using these techniques different variations viz. alloys, amorphous or polymers, and composites have been coated on the metallic BPPs. In our previous studies, we demonstrated a cost-effective electrodeposition technique to deposit corrosion resistance amorphous $\mathrm{Ni}$ $\mathrm{Cr}-\mathrm{P}[11,12]$ and Ni-Mo-Cr-P [13] coatings for AISI 1020 low carbon steel BPPs. Although the electrodeposited coatings are cost-effective, corrosion resistance is still not in the acceptable range of the US DOE target i.e. less than $1 \mu \mathrm{A} / \mathrm{cm}^{2}$.

In this work, we study the effectiveness of a carbonbased coating as an anticorrosive layer on stainless steel (304SS) BPPs. Graphene and its derivatives, such as graphene-related materials (GRMs), few-layered graphene $(\mathrm{FLG})$, graphene oxide $(\mathrm{GO})$, reduced graphene oxide ( $\mathrm{rGO}$ ), stand out among carbon-based coatings [14]. They show exceptional thermal, electrical, and anti-corrosive properties [15]. Several methods, such as CVD [7, 15], PVD [16], spray pyrolysis [17], spin coating [18], superheat vaporization of micro-droplet (SVM) method [19], and electrophoretic deposition (EPD) [20-22], have been proposed to deposit graphene and GO coatings. Electrophoretic deposition is not only a cost-effective method but also can deposit uniform coatings on substrates with intricate shapes [23]. This is critical because BPPs have complex and fine flow fields on the surface.

Ho et al. [24] show that steel with electrophoretically deposited GO coatings has better corrosion resistance than steel with graphene coatings in the acidic marine medium due to the formation of hydroxyl functional groups in GO coatings. Raza et al. [25] have optimized the electrophoretic deposition of graphene oxide on copper. The GO-Cu samples coated at $5 \mathrm{~V}$ and 10 s show $\sim 6$ times lower corrosion rate as compared to the bare copper in the marine environment. Jena et al. [23] reported the electrophoretic deposition of GO on 316 SS using both acidic ( $\mathrm{pH}$ 3.4) and alkaline ( $\mathrm{pH} 11$ ) suspensions. The $\mathrm{GO}$ coating from lower $\mathrm{pH}$ suspension exhibits a higher water contact angle due to densely agglomerated wrinkled microstructure. However, the GO coated 316 SS samples from alkaline suspension show lower water contact angle due to the uniform network morphology of GO. Chen et al. [26] also illustrate that the EPD technique can be used to coat graphene on $\mathrm{Ni}$-foams for applications such as electrodes in supercapacitors.
Till date, to the best of our knowledge, there have been no reports on the evaluation of electrophoretically deposited GO coatings on steel/stainless steel for BPPs in PEMFC. GO coating was electrophoretically deposited on 304SS, varying the deposition voltage. The surface roughness, contact angle, corrosion resistance (in a simulated PEMFC environment), and ICR were evaluated and compared with that of bare 304SS. These preliminary studies show that GO coatings on 304 SS can be used for improving the corrosion resistance and lowering the ICR of 304 SS BPPs.

\section{Materials and methods}

Graphene oxide was electrophoretically deposited on grade 304 Stainless Steel. The modified Hummer's method was used to synthesize the graphene oxide from graphite powder [27]. Here graphite flakes were crushed using a mortar and pestle and mixed with equal amounts of sodium nitrate dissolved in concentrated sulphuric acid. The solution was mixed in an ultrasonic bath for two hours and subsequently treated with an excess of potassium permanganate. Gradually deionized water (DI) water was added to dilute the solution till it reaches a brownish color solution. This solution was filtered to obtain a light brown solution of graphene oxide (referred to as $\mathrm{GO}$ ) suspension in water. The electrophoretic deposition was done on the $304 \mathrm{SS}$ anode, using a colloidal solution of GO as the electrolyte and a copper rod as the cathode. Prior to deposition, the $304 \mathrm{SS}$ substrate with the dimension of $(40 \mathrm{~mm}$ $\times 20 \mathrm{~mm}$ ) and $2 \mathrm{~mm}$ thickness was polished and ultrasonically cleaned in DI water for $15 \mathrm{~min}$, followed by surface activation in $5 \mathrm{wt} \% \mathrm{H}_{2} \mathrm{SO}_{4}$ solution. The surface-activated substrate was again cleaned using 2-propanol and deionized (DI) water, kept drying at room temperature. Next, the substrate was attached to anode and cathode and dipped into prepared GO prepared suspension. During the EPD process, as electricity is supplied to the setup shows the negatively charged particles get attracted towards the positive electrode side due to the influence of the electric field; hence after a given deposition time, deposition takes place [24].

A pre-determined voltage, between 1 and $12 \mathrm{~V}$, was applied for $5 \mathrm{~min}$ for depositing GO on 304SS. The microstructure of the deposited coatings was analyzed using a Carl Zeiss Merlin compact FESEM. The surface roughness of the samples was evaluated by the Taylor-Hobson type surface roughness tester (Surtronic 25). This method of surface roughness measurement uses a contact type stylus that traces a trail at a fixed load. The surface roughness $\left(R_{a}\right)$ is the average set of measurements of heights of peaks and valleys of surface profile. An average of three different 
trails across the area of the coating was done to obtain a mean value and its standard deviation.

Corrosion resistance study was done by conducting potentiodynamic polarization measurements at $70^{\circ} \mathrm{C}$ and purging air in an electrolyte solution consisting of $0.5 \mathrm{M}$ $\mathrm{H}_{2} \mathrm{SO}_{4}$ and $2 \mathrm{ppm}$ hydrofluoric acid $\{\mathrm{pH} 2.25( \pm 0.15)\}$ in deionized water with electrode surface area of $0.785 \mathrm{~cm}^{2}$ attached. This testing method is generally used to simulate the PEMFC environment [28]. Potentiodynamic scans were carried out at a rate of $0.17 \mathrm{mV} / \mathrm{s}$, with $\mathrm{Ag} / \mathrm{AgCl}$ and $\mathrm{Pt}$ wire as the reference electrode and counter electrode, respectively, using a Metrohms Autolab PGSTAT 302 N. The corrosion mechanism responsible for the degradation of the $\mathrm{GO}$ coated steel sample was evaluated by submerging the $\mathrm{GO}$ coated sample in the aggressive and simulated fuel cell electrolyte corrosion media for a prolonged period of 30 days to accelerate the corrosion process. The surface morphology of the sample was re-evaluated after 30 days using SEM.

The ICR was measured at a compaction force of 150 $\mathrm{N} / \mathrm{cm}^{2}$ using a previously described arrangement [29]. In this method, the resistance of a set-up with a GO coated BPP sandwiched between two gas diffusion layers (GDLs) and without the GO coated BPP is measured by applying a constant current of $0.1 \mathrm{~A} / \mathrm{cm}^{2}$ using Keysight N6700C low modular DC power source. The difference in the resistance is the ICR of the GO-coated BPPs. The water contact angle plays an important role in the efficient removal of water formed after the utilization of fuel. The water contact angle was measured by a profilometer with a $10 \mu \mathrm{L}$ droplet of water. The angle was digitally measured using ImageJ software.

\section{Results and discussion}

Figure $1(\mathrm{a}-\mathrm{e})$ show the scanning electron micrographs of the GO coating on steel at low magnification range, deposited at 1, 3, 5, 10, and $12 \mathrm{~V}$, respectively. The low magnification range of SEM micrograph has shown a better response to investigate surface properties than high magnification range, and also very helpful for comparison purpose with surface roughness analysis. It is evident from the micrographs that the surface defects decrease with an increase in deposition voltage from 1 to $10 \mathrm{~V}$ but drastically increases at $12 \mathrm{~V}$. The defects on the surface of the coatings deposited at $12 \mathrm{~V}$ are indicative of turbulence in the electrolyte during the deposition process Although it is difficult to comment on the closed porosity of coatings, the coating deposited at $10 \mathrm{~V}$ is very uniform with no visible surface pores. The uniformity and quality of the coatings corroborate well with surface roughness measurements, given in Table 1. The average surface roughness of the $\mathrm{GO}$ coatings decreases gradually from 1 to $10 \mathrm{~V}$, with a minimum of $0.16 \mu \mathrm{m}$ at $10 \mathrm{~V}$. As observed in the electron micrograph, the coating deposited at $12 \mathrm{~V}$ exhibits a roughness of $0.34 \mu \mathrm{m}$ with visible delamination during the roughness measurement. The increase in surface roughness is an indication of instability and turbulent flow during the deposition process.

Figure 2 shows the results of Raman spectroscopy performed on different deposition voltages of $3 \mathrm{~V}, 5 \mathrm{~V}, 7$ and $10 \mathrm{~V}$. The broader D-band at $1351 \mathrm{~cm}^{-1}$ shows the existence of structural disorder indicating the reduction in the size of the $\mathrm{sp}^{2}$ carbon domains in the basal plane due to extensive oxidation. The higher disorder in graphite due to oxidation leads to a broad G-band at $1596 \mathrm{~cm}^{-1}$ corresponding to the first-order scattering of $\mathrm{E}_{2 \mathrm{~g}}$ phonon of $\mathrm{sp}^{2}$ $\mathrm{C}$-atoms. Ideally, the absence of 2D-band in GO indicates that all the graphitic layers have been oxidized during the conversion of graphite to GO [30]. Hence, the Raman spectra of the coated $\mathrm{GO}$ at $3 \mathrm{~V}$ show no significant reduction in $G O$ via EPD. The subsequent increase in D/G intensity ratio from 0.96 to 0.99 with an increase in applied voltage up to $10 \mathrm{~V}$ indicates the presence of localized $\mathrm{sp}^{3}$ defects within the $\mathrm{sp}^{2}$ carbon network due to reduction via EPD. Here, a very broad and low intense 2D-band at around $2700 \mathrm{~cm}^{-1}$ confirms that the coated substrates were composed of multi-layered $\mathrm{GO}$ nano-sheets ( $>30$ layers) [24]. The appearance of an additional band $(D+G)$ at $2941 \mathrm{~cm}^{-1}$ shows lattice disorder in graphitic materials.

According to the previous reports [31, 32], single-layer graphene shows a sharp 2D-band whereas multi-layer graphene shows a very weak and broad 2D-band with a shift in peak to higher wavenumbers. Furthermore, Akhavan [33] reported that the $2 \mathrm{D} / \mathrm{G}$ intensity ratio of graphene oxide (GO) deposited on $\mathrm{SiO}_{2}$ substrate typically decreases with an increase in the number of graphene layers. In the present work, the $2 \mathrm{D} / \mathrm{G}$ intensity ratios of graphene oxide deposited on 304SS with an applied potential of $3 \mathrm{~V}, 5 \mathrm{~V}$, $7 \mathrm{~V}$, and $10 \mathrm{~V}$ were found to be $0.066,0.053,0.041$, and 0.037 , respectively. This confirms that with an increase in applied potential, the rate of deposition of GO increases, forming multi-layered graphene oxide nano-sheets on the substrate.

Potentiodynamic polarization test of $\mathrm{GO}$ coated on 304SS was conducted for chemical analysis at an acidic medium. As discussed previously, the partially reduced GO structure is expected to increase the corrosion rate, but in this case, particularly coatings deposited at $10 \mathrm{~V}$ have a very negligible amount of reduced $\mathrm{GO}$, and hence it may not adversely affect the corrosion resistance.

Figure 3 shows the potentiodynamic polarization plot for bare 304SS and GO coatings on 304 SS deposited $10 \mathrm{~V}$ in a simulated PEM fuel cell environment. Table 2 shows the corresponding values of corrosion potential 

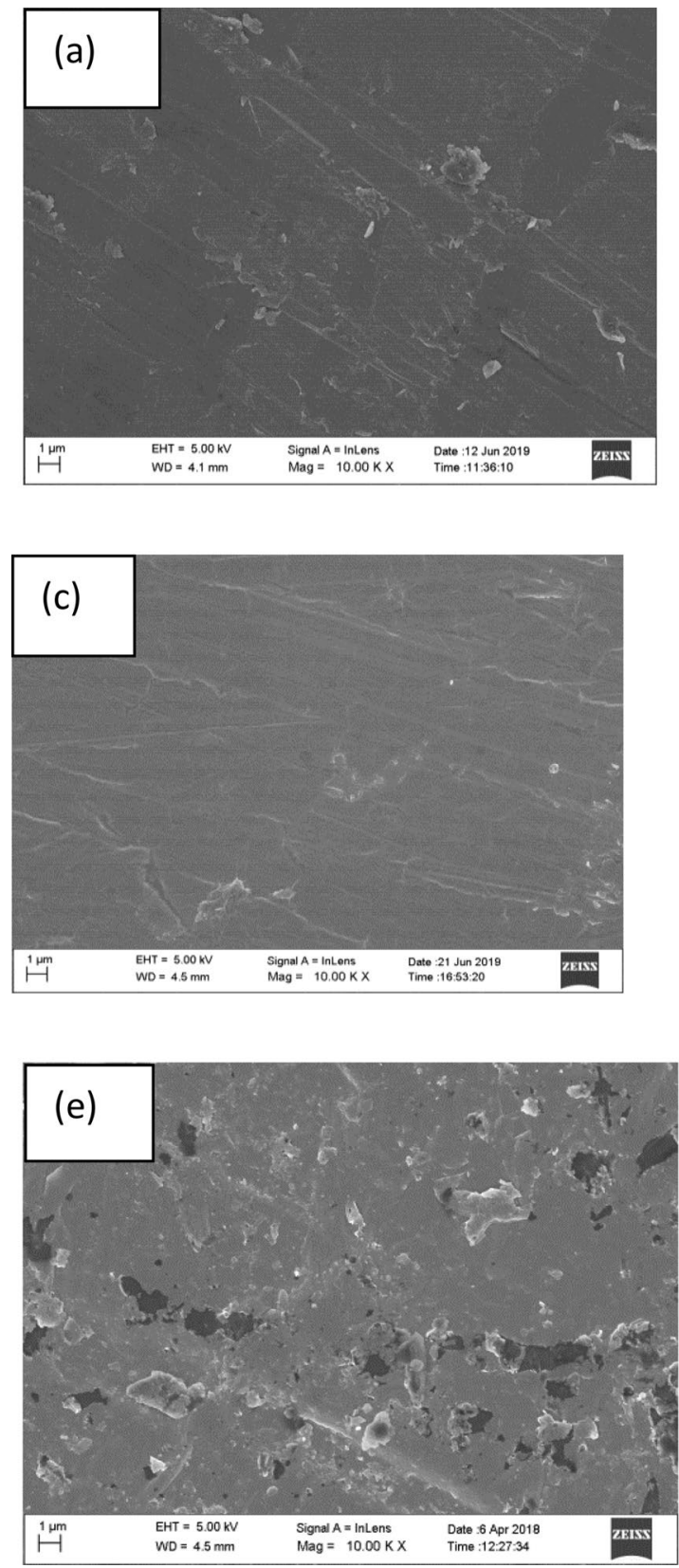
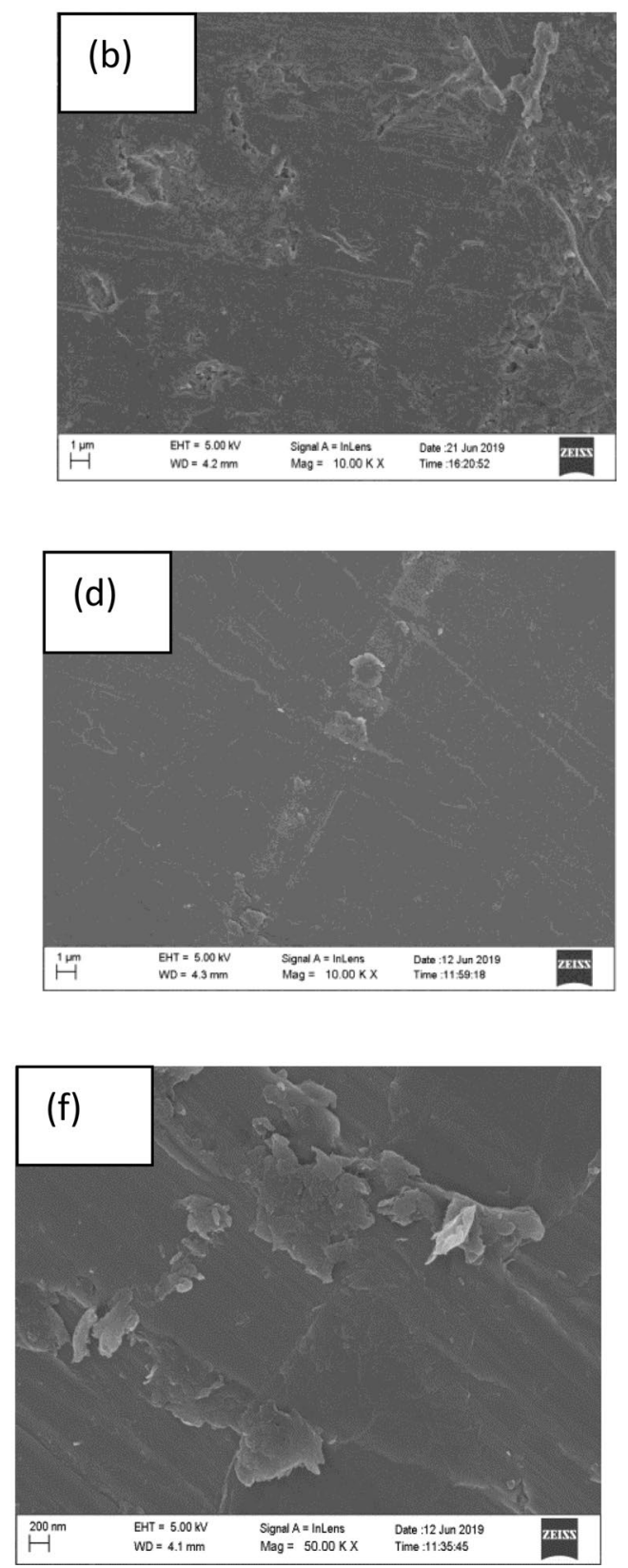

Fig. 1 a-e. SEM micrographs of GO coated steel deposited at a $1 \mathrm{~V}, \mathbf{b} 3 \mathrm{~V}, \mathbf{c} 5 \mathrm{~V}, \mathbf{d} 10 \mathrm{~V}$ and e $12 \mathrm{~V}$

Table 1 Surface roughness of the graphene oxide coated 304SS

\begin{tabular}{ll}
\hline Deposition Voltage (Volts) & $\begin{array}{l}\text { Mean surface } \\
\text { roughness }\left(\mathrm{R}_{\mathrm{a}}\right) \\
(\mu \mathrm{m})\end{array}$ \\
\hline 1 & $0.37 \pm 0.05$ \\
3 & $0.42 \pm 0.06$ \\
5 & $0.23 \pm 0.02$ \\
10 & $0.16 \pm 0.01$ \\
12 & $0.34 \pm 0.01$ \\
\hline
\end{tabular}

$\left(E_{\text {corr })}\right.$ and the corrosion current density $\left(i_{\text {corr }}\right)$. The OCP of bare 304 SS was found to be $-0.241 \mathrm{~V}$, while that of GO coated $3045 S$ was found to be $0.011 \mathrm{~V}$, indicating that the corrosion potential of 304SS is more than that of GO coated 304SS. It is to be noted that the other samples that were deposited did not have good adherence as they delaminated during the surface roughness measurement process, therefore corrosion tests were only conducted for coatings deposited at $10 \mathrm{~V}$. The corrosion current density in the cathodic environment for 


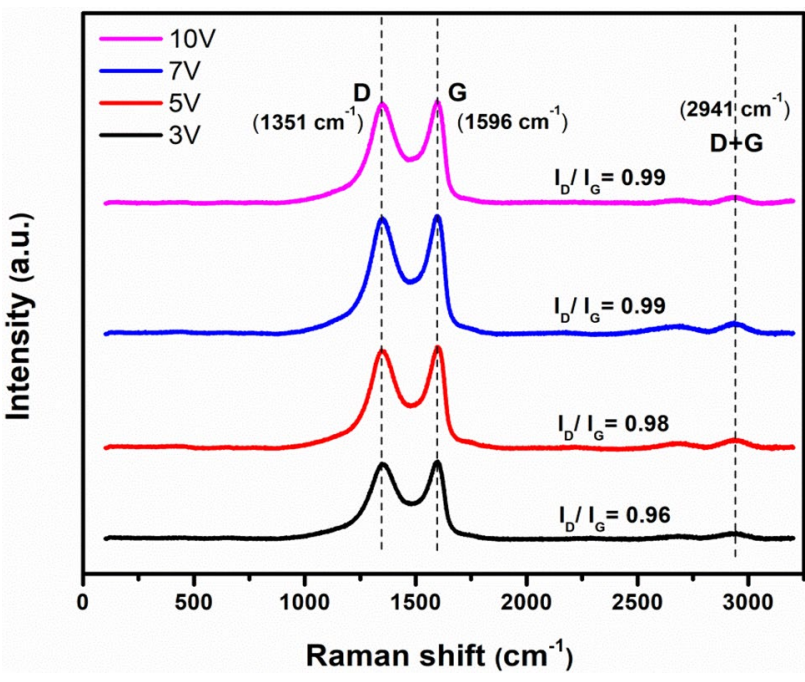

Fig. 2 Raman spectrograph of GO coated steel samples deposited at 3 to $10 \mathrm{~V}$

Table 2 Polarization scan parameters

\begin{tabular}{lll}
\hline & $\begin{array}{l}\text { Corrosion potential, } \\
\mathrm{E}_{\text {corr }}(\mathrm{V}) \mathrm{Vs} \mathrm{Ag/AgCl}\end{array}$ & $\begin{array}{l}\text { Corrosion current } \\
\text { density, } \mathrm{i}_{\text {corr }}(\mu \mathrm{A} / \\
\left.\mathrm{cm}^{2}\right)\end{array}$ \\
\hline Bare 304 SS & -0.29 & 468 \\
GO Coated 304 SS & -0.27 & 8.9 \\
\hline
\end{tabular}

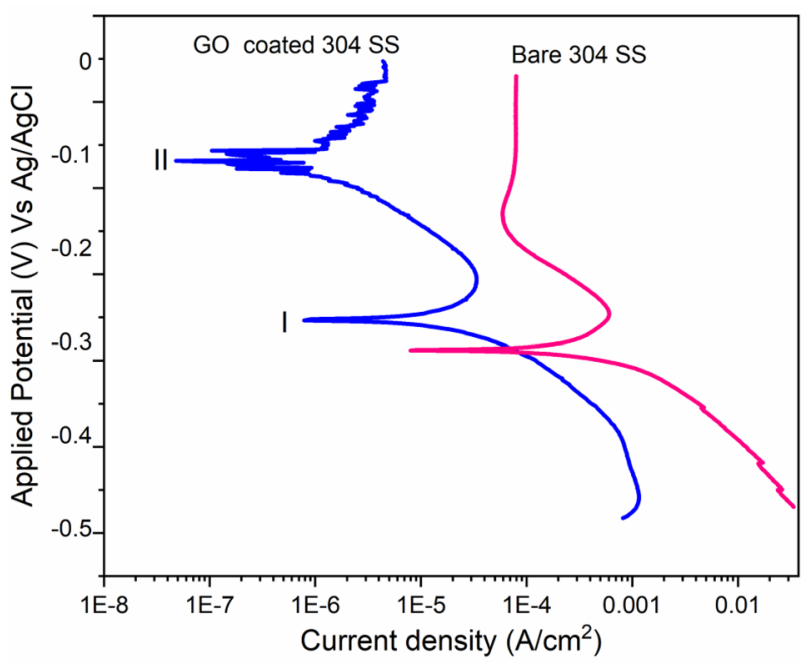

Fig. 3 Potentiodynamic polarization curves of GO coated 304SS and bare $304 \mathrm{SS}$ in simulated PEM cell electrolyte $\left(0.5 \mathrm{M} \mathrm{H}_{2} \mathrm{SO}_{4}\right.$ and 2 ppm HF)

bare 304 SS and GO coated 304 SS is $468 \mu \mathrm{A} / \mathrm{cm}^{2}$ and $8.9 \mu \mathrm{A} / \mathrm{cm}^{2}$, respectively. The GO coating improved the corrosion current density by 2 orders in magnitude and is close to the US-DOE requirement of $1 \mu \mathrm{A} / \mathrm{cm}^{2}$ requirement.

The mechanism of corrosion can be understood from the polarization scan of the GO coated sample shown in Fig. 3. The figure shows there are two peaks observed in the scan, denoted by I and II, at corrosion potentials of -0.3 and $-0.1 \mathrm{~V}$, respectively. The occurrence of multiple peaks, hence multiple corrosion potentials, during potentiodynamic scans has not been discussed at all for either graphene or graphene oxide coatings.

Some publications have reported that the presence of multiple peaks in the polarization scan indicates the multiple corrosion mechanisms activated in the simulating environment [34, 36]. Kelly et al. [34] have reported as many as three different corrosion potentials for stainless steel in sulphuric acid, and it has been attributed to the change in concentration of sulphuric acid and oxygen in the electrolyte. Abdullah et al. [35] have also observed two peaks during the potentiodynamic polarization study of $304 \mathrm{SS}$ in $0.5 \mathrm{M} \mathrm{H}_{2} \mathrm{SO}_{4}$ solution. The multiple peaks are mainly due to the different oxidation mechanisms of $\mathrm{Fe}$ and $\mathrm{Cr}$ in the steel sample in the acidic medium at different potentials. Whereas Li et al. [36] have shown that the occurrence of multiple corrosion potentials is related to the potentiodynamic scan rate, the concentration of the electrolyte, and also the microstructure of the material. Here since both the corrosion potentials are negative, they are both cathodic in nature. It may be construed in similar lines to previous publications on corrosion of stainless steel in sulphuric acid, that two different corrosion mechanisms are active here [34].

Figures 4 and 5 show the photographs and SEM micrographs of the bare 304SS and GO coated 304SS, respectively, after prolonged corrosion in simulated fuel cell environment. The micrographs in Figs. 4b, $5 \mathrm{~b}$ clearly shows the presence of corrosion pits in the sample. The corrosion is more pronounced for the uncoated bare 304SS. The EDS data of the corroded sample, collected with the FESEM, shows a significant increase in the $\mathrm{C}: \mathrm{O}$ ratio. It increases from 3.6:1 in the as-deposited sample un-corroded sample, to 5:1 after the prolonged immersion, which indicates that the GO in the coating gets reduced to graphene during the corrosion process.

The evolution of oxygen and hydroxyl groups from the $\mathrm{GO}$ structure may be the dominant reason for the occurrence of the second peak in the Tafel plot in Fig. 3. However, pitting due to corrosion in the bare 304SS plates, shown in Fig. 4, when exposed to prolonged period in the simulated PEMFC environment has a different appearance with enlarged pits non-uniformly distributed on the exposed surface [37].

Corrosion in a fuel cell is mostly due to the water vapor and water interaction with the bipolar plate. Therefore, 
Fig. 4 a Photograph and b SEM micrograph bare 304SS after prolonged corrosion

Fig. 5 a Photograph and $\mathbf{b}$ SEM micrograph of GO coated 304SS after prolonged corrosion
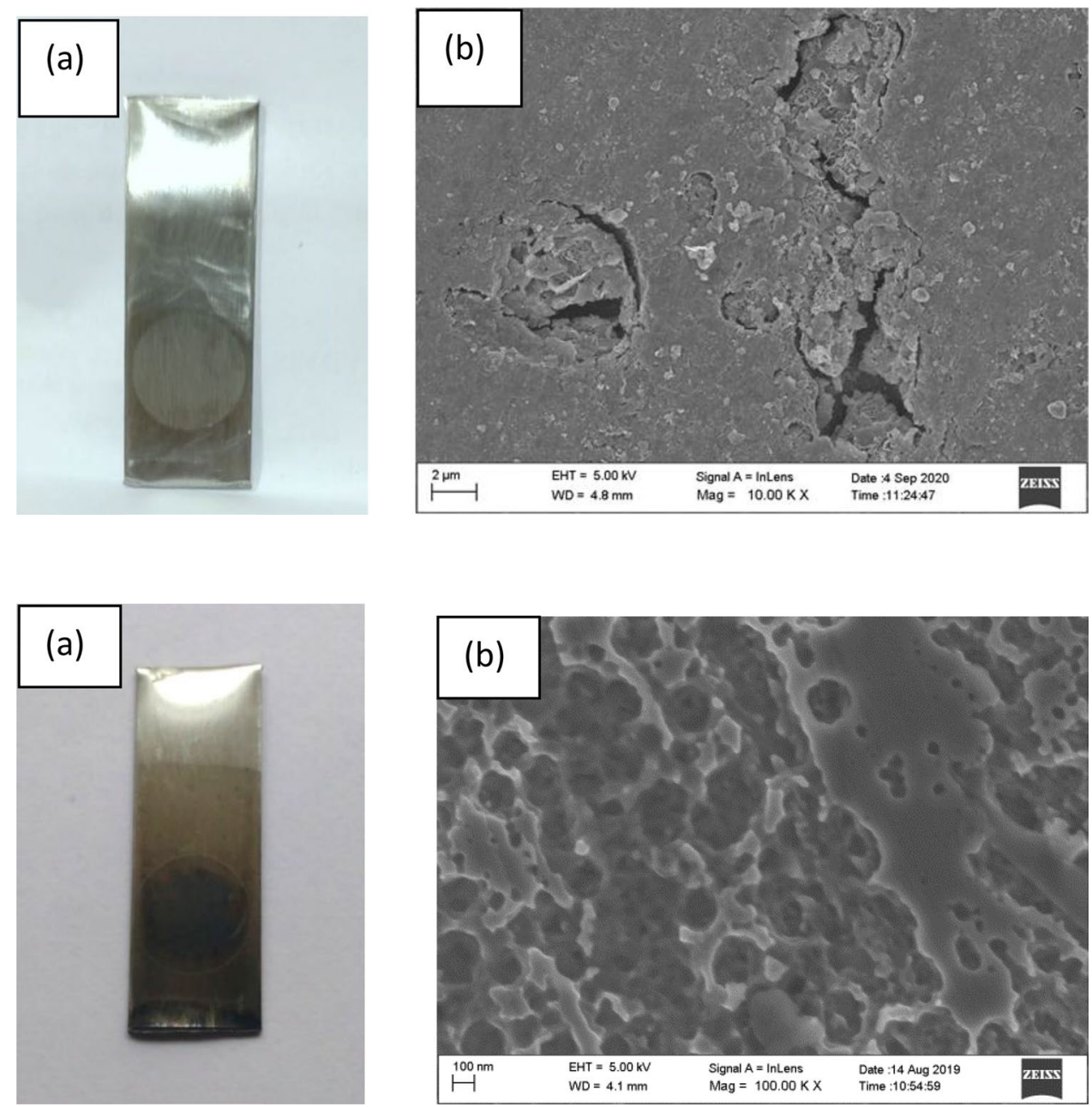

corrosion of the BPPs can be minimized by making them hydrophobic. The hydrophobicity of the GO coated 304SS was tested by evaluating its water contact angle. Figure 6 shows the photograph taken for a drop of water floating on the GO coated sample. The water contact angle, as measured by the ImageJ software to be $94.5^{\circ}$. The water contact angle is an indication of the hydrophobic or hydrophilic nature of the coating [38]. The 304 SS is normally highly wettable, i.e. hydrophilic in nature due to the attached functional groups 38. The deposition of GO improves the hydrophobicity of the sample, shown in Fig. 6. It is commonly observed that GO is highly water repellent [39]. The increase in hydrophobicity is attributed to the presence of a non-covalent bond structure in graphene oxide, which restricts the formation of hydrogen bonding with the water molecule [7]. However, when continuously in contact with water molecules or acidic medium, as was conducted during the prolonged corrosion test, GO coated 304SS is likely to corrode and turn hydrophilic in nature. It can be clearly seen in Fig. 7 i.e. contact angle measured through ImageJ software was $77.8^{\circ}$.

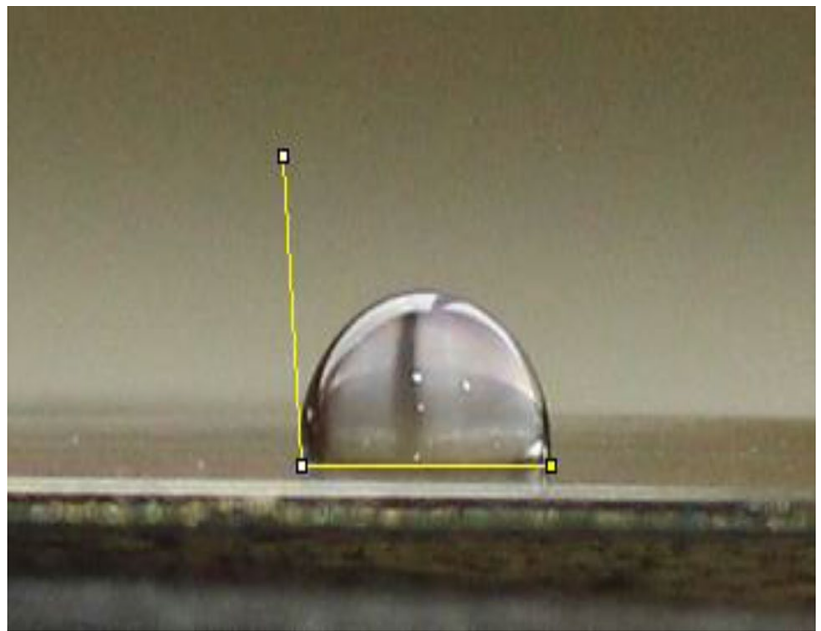

Fig. 6 Photograph of a water droplet placed on GO coated 304SS $\left(\theta=94^{\circ}\right)$ 
Fig. 7 Photograph of water droplet placed on GO coated 304SS after prolonged corrosion $\left(\theta=77^{\circ}\right)$

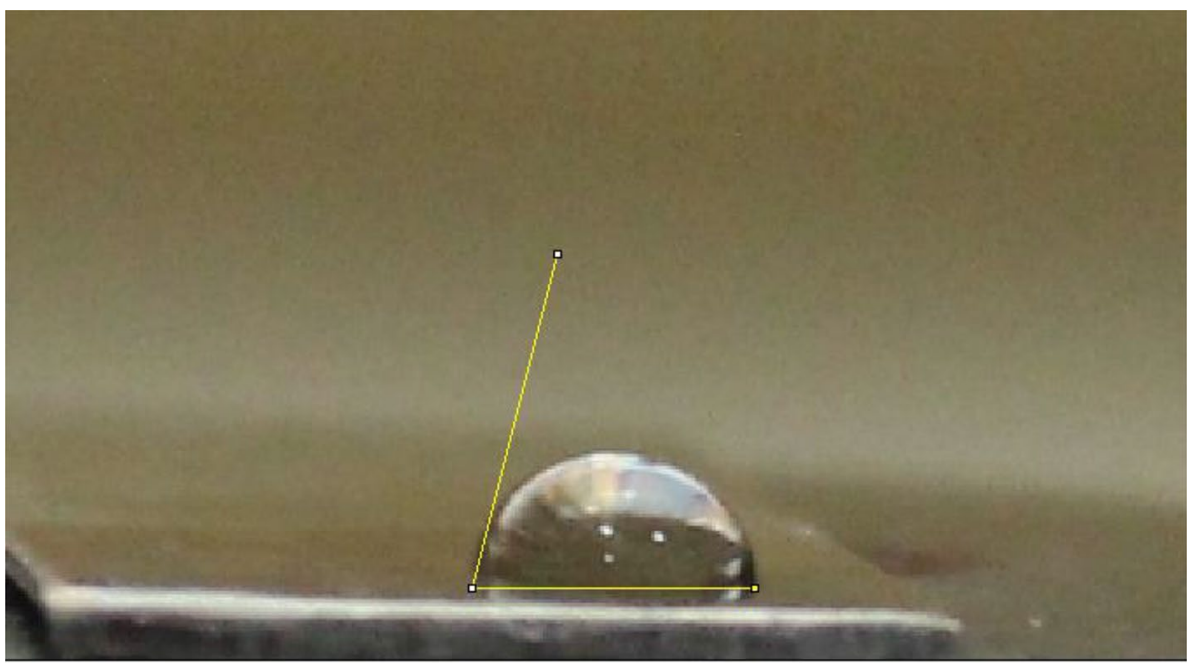

The ICR with the GDL, compacted at $150 \mathrm{~N} / \mathrm{cm}^{2}$ for the GO coated 304 steel was calculated to be $19.3 \mathrm{~m} \Omega \mathrm{cm}^{2}$ while that for bare 304SS was calculated to be $35.9 \mathrm{~m} \Omega$ $\mathrm{cm}^{2}$. The ICR value of the $\mathrm{GO}$ coated $304 \mathrm{SS}$ has decreased by almost twice as compared to that of bare steel, and lies close to that specified by DOE $\left(<20 \mathrm{~m} \Omega \mathrm{cm}^{2}\right)$.

The GO coated 304 SS substrate, or any other low-cost commercially available metal can be a suitable candidate for PEM fuel cell BPP. The GO coating deposited at $10 \mathrm{~V}$ shows a smooth surface, indicating fewer surface irregularities. The coatings deposited at higher voltage $(12 \mathrm{~V})$ show indication of turbulent behavior during a deposition that increases its surface roughness and reduces its adherence, and increases its surface roughness. However, all coatings show the presence of partially reduced graphene oxide in them. The resistance to fuel, oxidant, and exhaust gas flow decreases with an increase in the smoothness of the surface, which helps in uniform distribution of the reacting gases and lowering of the concentration polarization. Although the result shows that the deposited GO surface is smooth, it is difficult to comment on the closed internal porosity. Closed pores may not adversely affect the corrosion resistance, but they may affect the ICR due to a decrease in the area of conduction. That said, ICR of GO coated BPP does not show any increase compared to bare 304 SS, which confirms that the suitability of coatings for metallic BPPs.

The metallic BPPs corrode when they react with $\mathrm{SO}_{4}{ }^{2-}$ and $\mathrm{F}^{-}$ions \{present in the polymer electrolyte\}. This study shows that corrosion resistance of the metallic BPPs can be improved by coating them with electrophoretically deposited $\mathrm{GO}$ coating. The $\mathrm{GO}$ coating on the surface prevents the simulated electrolyte solution from entering and react with a metallic substrate. However, it has been reported earlier that $\mathrm{sp}^{3}$ carbon present in GO preferentially oxidizes in the acidic medium [40]. This might be the reason for the observation of corroded pits in Fig. 5b. The inclusion of high oxygenated functional groups by the addition of a strong oxidizing agent has been shown to improve the corrosion resistance of graphene oxide coatings in general [24]. The corrosion resistance can also be improved by increasing the hydrophobic nature of the GO coatings, which also helps in the easy removal of exhaust gases.

\section{Conclusion}

Graphene oxide was successfully deposited on SS304 by the electrophoretic deposition technique. The deposition voltage was systematically varied from 1 to $12 \mathrm{~V}$. The obtained GO coated 304SS was characterized systematically for surface morphology, composition, roughness, and defects to test the coating quality. All coatings have a smooth non-distinct surface morphology. In comparison of the different coatings against their characteristics, the GO coating deposited at $10 \mathrm{~V}$ had the lowest $\left(R_{a}\right)$ surface roughness with consistent coating adhesion (there was no delamination). Whereas that deposited at $12 \mathrm{~V}$ had the highest roughness, with visible delamination on the application of pressure. The Raman spectroscopy of the samples shows that there is some un-oxidized graphene present in the coatings that will affect its interaction with water and water vapor. In this respect, the water contact angle was $94.5^{\circ}$ showing inclination towards hydrophobicity of the $\mathrm{GO}$ coatings.

The GO coated sample deposited at $10 \mathrm{~V}$ was further evaluated for corrosion by electrochemical testing by a potentiostat. Potentiodynamic polarization scans were conducted at the PEM fuel cell operating condition. The results obtained from the Tafel polarization curve show that the cathodic corrosion current density has improved 
by two orders and is close to the $1 \mu \mathrm{A} / \mathrm{cm}^{2}$ mark set by US-DOE. It should be noted here that the polarization scan shows the presence of multiple peaks (I and II), which may be attributed to two different corrosion mechanisms being active at these scan rates. Accelerated corrosion by prolonged immersion in the simulated PEMFC media shows that pitting corrosion is the prevalent corrosion mechanism. The interfacial contact resistance of the GO coated 304 SS decreased by two times with that compared to bare 304SS.

Acknowledgements The authors, P. Mandal and S. Roy acknowledge the receipt of grants from the Department of Science and Technology, SERB, Govt of India (EMR/2016/002927) towards completion of this work.

\section{Declarations}

Conflict of interest The authors declare that they have no competing interests

Open Access This article is licensed under a Creative Commons Attribution 4.0 International License, which permits use, sharing, adaptation, distribution and reproduction in any medium or format, as long as you give appropriate credit to the original author(s) and the source, provide a link to the Creative Commons licence, and indicate if changes were made. The images or other third party material in this article are included in the article's Creative Commons licence, unless indicated otherwise in a credit line to the material. If material is not included in the article's Creative Commons licence and your intended use is not permitted by statutory regulation or exceeds the permitted use, you will need to obtain permission directly from the copyright holder. To view a copy of this licence, visit http://creativecommons. org/licenses/by/4.0/.

\section{References}

1. Karimi S, Fraser N, Roberts B, Foulkes FR (2012) A review of metallic bipolar plates for proton exchange membrane fuel cells: Materials and fabrication methods. Adv Mater Sci Eng. https://doi.org/10.1155/2012/828070

2. Fuel cell technologies office technical targets: bipolar plates for transportation applications. In: United States - Dep. Energy. energy.gov/eere/fuelcells/doe-technical-targets-polymer-elect rolyte-membrane-fuel-cell-components. Accessed 10 May 2019

3. Tawfik H, Hung Y, Mahajan D (2007) Metal bipolar plates for PEM fuel cell-a review. J Power Sources 163:755-767. https://doi.org/ 10.1016/j.jpowsour.2006.09.088

4. Mawdsley JR, Carter JD, Wang X et al (2013) Composite-coated aluminum bipolar plates for PEM fuel cells. J Power Sources 231:106-112

5. Antunes RA, De Oliveira MCL, Ett G, Ett V (2011) Carbon materials in composite bipolar plates for polymer electrolyte membrane fuel cells: a review of the main challenges to improve electrical performance. J Power Sources 196:2945-2961

6. Kahraman H, Cevik I, Dündar F, Ficici F (2016) The corrosion resistance behaviors of metallic bipolar plates for PEMFC coated with physical vapor deposition (PVD): an experimental study. Arab J Sci Eng 41:1961-1968. https://doi.org/10.1007/ s13369-016-2058-X

SN Applied Sciences
7. Pu NW, Shi GN, Liu YM et al (2015) Graphene grown on stainless steel as a high-performance and ecofriendly anti-corrosion coating for polymer electrolyte membrane fuel cell bipolar plates. J Power Sources 282:248-256. https://doi.org/10. 1016/j.jpowsour.2015.02.055

8. Haghighat Ghahfarokhi H, Saatchi A, Monirvaghefi SM (2016) Corrosion investigation of chromium nitride and chromium carbide coatings for PEM fuel cell bipolar plates in simulated cathode condition. Fuel Cells 16:356-364. https://doi.org/10. 1002/fuce.201600005

9. Nikam VV, Reddy RG, Collins SR et al (2008) Corrosion resistant low temperature carburized SS 316 as bipolar plate material for PEMFC application. Electrochim Acta 53:2743-2750. https://doi.org/10.1016/j.electacta.2007.10.061

10. Rajaei V, Rashtchi H, Raeissi K, Shamanian M (2017) The study of Ni-based nano-crystalline and amorphous alloy coatings on AISI 304 stainless steel for PEM fuel cell bipolar plate application. Int J Hydrog Energy 42:14264-14278. https://doi.org/10. 1016/j.ijhydene.2017.04.098

11. Chanda UK, Behera A, Roy S, Pati S (2018) Evaluation of Ni-Cr-P coatings electrodeposited on low carbon steel bipolar plates for polymer electrolyte membrane fuel cell. Int J Hydrog Energy 43:23430-23440. https://doi.org/10.1016/j.ijhydene. 2018.10.218

12. Chanda UK, Padhee SP, Pathak AD et al (2019) Effect of $\mathrm{Cr}$ content on the corrosion resistance of $\mathrm{Ni}-\mathrm{Cr}-\mathrm{P}$ coatings for PEMFC metallic bipolar plates. Mater Renew Sustain Energy 8:20. https://doi.org/10.1007/s40243-019-0158-8

13. Chanda UK, Padhee SP, Pandey AK et al (2020) Electrodeposited $\mathrm{Ni}-\mathrm{Mo}-\mathrm{Cr}-\mathrm{P}$ coatings for AISI 1020 steel bipolar plates. Int J Hydrog Energy 45:21892-21904. https://doi.org/10.1016/j. ijhydene.2020.06.014

14. Alrashed MM, Soucek MD, Jana SC (2019) Role of graphene oxide and functionalized graphene oxide in protective hybrid coatings. Prog Org Coat 134:197-208

15. Narula U, Tan CM (2016) Determining the parameters of importance of a graphene synthesis process using designof-experiments method. Appl Sci 6:204

16. Gilje $S$, Han S, Wang $M$ et al (2007) A chemical route to graphene for device applications. Nano Lett 7:3394-3398

17. Tung VC, Allen MJ, Yang Y, Kaner RB (2009) High-throughput solution processing of large-scale graphene. Nat Nanotechnol 4:25

18. Guo Y, Di C, Liu H et al (2010) General Route toward patterning of graphene oxide by a combination of wettability modulation and spin-coating. ACS Nano 4:5749-5754. https://doi.org/10. $1021 / \mathrm{nn} 101463 \mathrm{j}$

19. Lee GW, Shim GH, Kim JM et al (2020) Two/three-dimensional reduced graphene oxide coating for porous flow distributor in polymer electrolyte membrane fuel cell. Int J Hydrog Energy 45(23):12972-12981

20. Raza MA, Ali A, Ghauri FA et al (2017) Electrochemical behavior of graphene coatings deposited on copper metal by electrophoretic deposition and chemical vapor deposition. Surf Coat Technol 332:112-119

21. Usha Kiran N, Dey S, Singh BP, Besra L (2017) Graphene coating on copper by electrophoretic deposition for corrosion prevention. Coatings 7:214

22. Chavez-Valdez A, Shaffer MSP, Boccaccini AR (2013) Applications of graphene electrophoretic deposition. A review. J Phys Chem B 117:1502-1515. https://doi.org/10.1021/jp3064917

23. Jena G, Vanithakumari SC, Thinaharan C et al (2018) Anodic electrophoretic deposition of graphene oxide on $316 \mathrm{~L}$ stainless steel with $\mathrm{pH}$-dependent microstructures. J Bio TriboCorrosion 4:20 
24. Ho C-Y, Huang S-M, Lee S-T, Chang Y-J (2019) Evaluation of synthesized graphene oxide as corrosion protection film coating on steel substrate by electrophoretic deposition. Appl Surf Sci 477:226-231

25. Raza MA, Rehman ZU, Ghauri FA et al (2016) Corrosion study of electrophoretically deposited graphene oxide coatings on copper metal. Thin Solid Films 620:150-159

26. Chen Y, Zhang X, Yu P, Ma Y (2010) Electrophoretic deposition of graphene nanosheets on nickel foams for electrochemical capacitors. J Power Sources 195:3031-3035

27. Mandal P, Kiran UN, Pati S, Roy S (2020) Investigation of the effects of electrophoretic deposition parameters on 304SS steel coated with graphene oxide for PEMFC application. Mater Today Proc 26:654-659. https://doi.org/10.1016/j.matpr. 2019.12.360

28. Wang Z, Feng K, Li Z et al (2016) Self-passivating carbon film as bipolar plate protective coating in polymer electrolyte membrane fuel cell. Int J Hydrog Energy 41:5783-5792. https://doi. org/10.1016/j.ijhydene.2016.02.076

29. Avasarala B, Haldar P (2009) Effect of surface roughness of composite bipolar plates on the contact resistance of a proton exchange membrane fuel cell. J Power Sources 188:225-229. https://doi.org/10.1016/j.jpowsour.2008.11.063

30. Singh BP, Nayak S, Nanda KK et al (2013) The production of a corrosion resistant graphene reinforced composite coating on copper by electrophoretic deposition. Carbon N Y 61:47-56. https://doi.org/10.1016/j.carbon.2013.04.063

31. Reina A, Son H, Jiao L et al (2008) Transferring and identification of single- and few-layer graphene on arbitrary substrates. J Phys Chem C 112:17741-17744. https://doi.org/10.1021/ jp807380s

32. Ferrari AC, Meyer JC, Scardaci V et al (2006) Raman spectrum of graphene and graphene layers. Phys Rev Lett 97:187401. https://doi.org/10.1103/PhysRevLett.97.187401
33. Akhavan O (2015) Bacteriorhodopsin as a superior substitute for hydrazine in chemical reduction of single-layer graphene oxide sheets. Carbon N Y 81:158-166. https://doi.org/10. 1016/j.carbon.2014.09.044

34. Kelly RG, Scully JR, Shoesmith D, Buchheit RG (2002) Electrochemical techniques in corrosion science and engineering. CRC Press, Florida

35. Abdallah M (2003) Corrosion behaviour of 304 stainless steel in sulphuric acid solutions and its inhibition by some substituted pyrazolones. Mater Chem Phys 82:786-792

36. Li YJ, Wang YG, An B et al (2016) A practical anodic and cathodic curve intersection model to understand multiple corrosion potentials of fe-based glassy alloys in $\mathrm{OH}$-contained solutions. PLoS One 11(1), e0146421

37. Mele C, Bozzini B (2012) Corrosion performance of austenitic stainless steel bipolar plates for nafion-and room-temperature ionic-liquid-based PEMFCs. Open Fuels Energy Sci J 5:47-52

38. Zhang Z, Zhao J, Lei $Y$ et al (2020) Preparation of intricate nanostructures on 304 stainless steel surface by SiO2-assisted HF etching for high superhydrophobicity. Colloids Surf A Physicochem Eng Asp 586:124287. https://doi.org/10.1016/j.colsu rfa.2019.124287

39. Ding R, Li W, Wang $X$ et al (2018) A brief review of corrosion protective films and coatings based on graphene and graphene oxide. J Alloys Compd 764:1039-1055

40. Yang S, Yang Y, He P et al (2017) Insights into the oxidation mechanism of sp2-sp3 hybrid carbon materials: preparation of a water-soluble 2D porous conductive network and detectable molecule separation. Langmuir 33:913-919. https://doi. org/10.1021/acs.langmuir.6b03937

Publisher's Note Springer Nature remains neutral with regard to jurisdictional claims in published maps and institutional affiliations. 